\title{
Placentation in the American Beaver (Castor canadensis) '
}

\author{
THEODORE V. FISCHER \\ Department of Anatomy, The University of Michigan, \\ Ann Arbor, Michigan 48104
}

\begin{abstract}
Implantation in the beaver is superficial and antimesometrial. The embryonic disc occupies one side of the flattened mesometrial hemisphere of the large blastocyst. An endometrial papilla, unique to the beaver, forms on the mesometrial uterine wall just prior to chorioallantoic contact. The reniform placenta then develops around this papilla. Amniogenesis is by folding. A transient choriovitelline placenta develops very early. Yolk sac inversion is late, and the bilaminar omphalopleure is partially retained throughout gestation. The chorion persists until term as two paraplacental membranes. A large permanent allantoic vesicle is present. The labyrinthine placenta has a lobulate architecture. It possesses a hemodichorial barrier, the inner layer being syncytial and the outer cellular. Maternal blood is supplied by two arterial channels which do not penetrate the labyrinth, and is drained by a single, central venous channel. A large basal subplacenta develops by trophoblastic invasion of the endometrial papilla, and becomes quite massive at term. Its function is unknown. Except for this specialized subplacenta, all the fetal membrane characteristics are typical of the primitive sciuromorph group, to which the Castoridae seem to be closely related.
\end{abstract}

The mammalian superfamily Castoroidea, which contains only one recent family, Castoridae, is of uncertain relationships among rodents. Characteristics of the skull and dentition rule out affinities with the suborders Myomorpha and Caviomorpha (Romer, '66). Its dentition shows certain similarities to the Sciuromorpha, but skull characters appear to set it apart from this suborder also. Romer ('66) lists the group as unassigned to any suborder, but indicates a presumed sciuromorph ancestry.

In addition to skeletal elements, comparisons of soft tissues of recent groups are valuable in detecting affinities between them. This is especially true of the reproductive system and fetal membranes. Since fetal membranes are relatively sheltered from external environmental forces, they tend to be more evolutionarily conservative than many other systems. Characteristics of fetal membrane development thus can be important in the phylogenetic classification of mammals (Mossman, '37, '53). Therefore, an analysis of placentation in the beaver (Castor canadensis) could be of value in understanding the relationships of the Castoroidea.

Two extensive papers (Willey, '12, '14) and a short comparative note (Mossman, '57) comprise the literature on beaver placentation. The early papers are quite comprehensive, but use archaic nomenclature. Willey ('12) also expresses an individualistic definition of terms, which leads to uncertainty and obscures comparison with other species.

Mossman ('57) observed two distinct layers between maternal blood and fetal capillaries in the beaver placenta. Because of the obvious separation of layers, he suggested that this placenta may have an endothelio-chorial barrier. This possibility, which has been reported in only one other rodent group (King and Tibbits, '69), required further study for evaluation.

The present research was undertaken to describe the development of the fetal membranes in the beaver (Castor canadensis),

1 This work was supported in part by General Research Support grant FR-05383-06 of the University of Michigan Medical School, and in part by Institutional Michigan Medical School, and in part by Institutional
Research grant IN-401 to The University of Michigan from the American Cancer Society. 
to determine the nature of its placental barrier, and to contribute to our understanding of the phylogenetic relationships of the Castoroidea.

\section{MATERIALS AND METHODS}

Specimens of beaver preplacental stages and early placentation were made available by the Hubrecht Laboratory, Utrecht, Holland. Reproductive tracts in various stages near midpregnancy were collected and fixed in the field (alcohol/formalin/acetic acid (AFA)) and sent to our laboratory for further preparation. Two beavers nearing term were killed and pieces of placenta were fixed in $2 \%$ glutaraldehyde (postfixed in osmium tetroxide) for electron microscopy. Other gestation sacs and placentae from these animals were fixed in neutral buffered $10 \%$ formalin or AFA.

Selected sections of the various stages were stained with all or most of the following methods: hematoxylin and eosin, periodic acid-Schiff (PAS) reaction, Movat pentachrome (Movat, '55), Alcian blue or colloidal iron (of ten with PAS), and silver reticular fiber stain.

Gross dissections of the placenta and fetal membranes were made of several of the midterm gestation sacs.

\section{OBSERVATIONS}

\section{The preplacental period}

The blastocyst. Three blastocysts in stages of implantation were studied. Following loss of the zona pellucida, the blastocyst evidently expands greatly. The specimens available varied from $1.5 \mathrm{~mm}$ to $2.5 \mathrm{~mm}$ in diameter.

The first antimesometrial attachment is superficial (fig. 9). Several groups of abembryonic trophoblastic cells insinuate themselves within the epithelium of the spheroidal implantation chamber. In this way, multiple attachrnent cones are formed (fig. 11). The equatorial region of the older blastocysts is attached by a ring of these cones. From this ring, the embryonic hemisphere is suspended into the narrowed uterine lumen on the mesometrial side of the implantation chamber, and is thereby flattened into the "keel" described by Willey ('14) (fig. 10).

The free abembryonic trophoblastic cells contiguous to the attachment cones differ- entiate into mononuclear giant cells which attract and engulf maternal leucocytes. Large numbers of leucocytes are present in the antimesometrial decidua, between epithelial cells, free in the uterine lumen, and engulfed by the trophoblastic giant cells (figs. 12, 13). 'This attraction of leucocytes by giant cells was mentioned by Willey ('14) and has been reported on a lesser scale in the hamster (Orsini, '54). The phenomenon occurs also in man, the rat and Mongolian gerbil (unpublished observations of A. D. Floyd and author). Its significance is as yet unclear.

While the conceptus is attached only by the implantation cones, the three germ layers have already differentiated to form an embryonic disc covering one side of the "keel" (fig. 10). The ectoderm of the disc is now continuous with the outer trophoblast, but it is possible that a previous Rauber's layer of trophoblast once covered it. Endoderm lines the entire blastocyst; it becomes columnar in the region of the embryonic disc, but is cuboidal to squamous elsewhere. Between these layers is the primitive streak mesoderm, which has anterior and lateral extensions (fig. 10).

Stages of amniogenesis were unavailable for study. Willey ('14) reports amniogenesis to occur by folding. Since the embryonic disc is on the blastocyst surface, this must certainly be the method.

Endometrial changes for placentation. During the expansion and development of the preplacental blastocyst, the endometrium of the mesometrial side is being modified to anticipate placentation. The epithelium, normally simple columnar, becomes stratified, and an ellipsoidal epithelial lamina of several cells thickness proliferates into the adjacent stroma, encircling the prospective placental site (fig. 1). Numerous epithelial cords project outward from both surfaces of the lamina. The stroma surrounding them shows no tendency towards decidualization. A rich blood supply develops in the stroma enclosed by the lamina, and large sinusoidal vessels fill the spaces between adjacent epithelial cords (fig. 1).

The next stages of endometrial development and incipient placental contact are unavailable. However, in the earliest placental stage examined the uterine lumen 
is much expanded. An endometrial papilla projects centrally and is capped on all sides by the young placenta (figs. 3,16 ). It is surmised that a split occurs in the middle

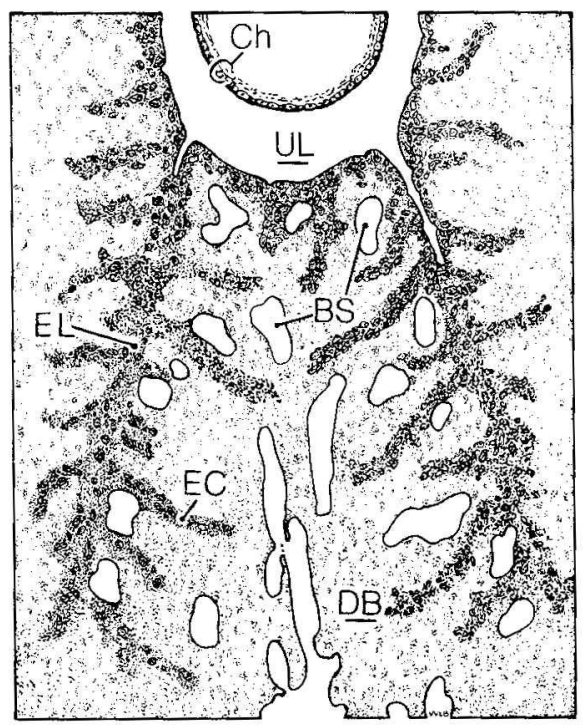

Fig. 1 Diagram of the mesometrial endometrium prior to contact by the chorion ( $\mathrm{Ch}$ ). Two epithelial laminae (EL) penetrate into the pro. spective decidua basalis (DB) and begin to split. Numerous epithelial cords (EC) project from the laminae. Maternal blood sinusoids (BS) come into close proximity to these cords and Iaminae. Uterine lumen, UL. of the epithelial lamina (there was some indication of incipient splitting) and that the lateral sides diverge to form part of the uterine luminal surface (figs. 2, 3). A central papilla (or ridge) remains having a

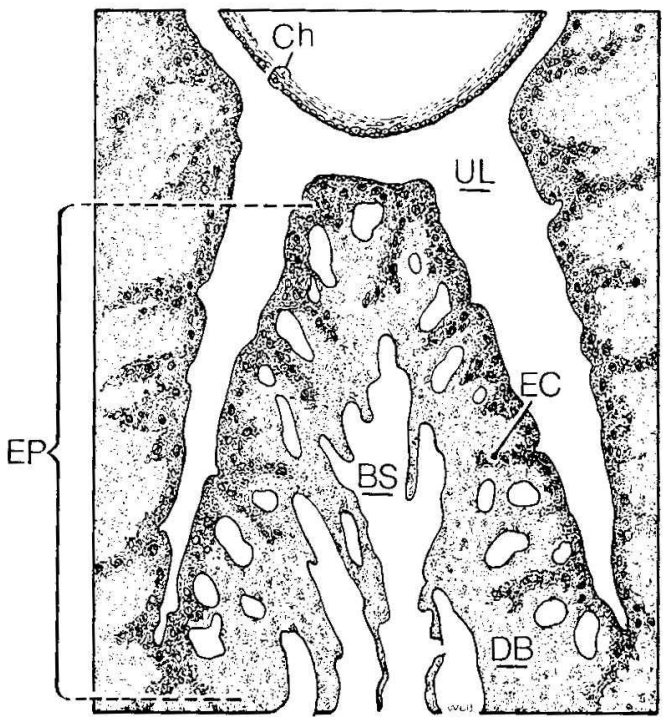

Fig. 2 Diagram of a hypothetical stage showing the transition between conditions in figures 1 and 3 . The splitting of the epithelial laminae continues to their bases to form an endometrial papilla (EP) projecting into the uterine lumen (UL) from the basal decidua (DB). Blood sinusoids (BS) are more pronounced. Chorion, $\mathrm{Ch}$.

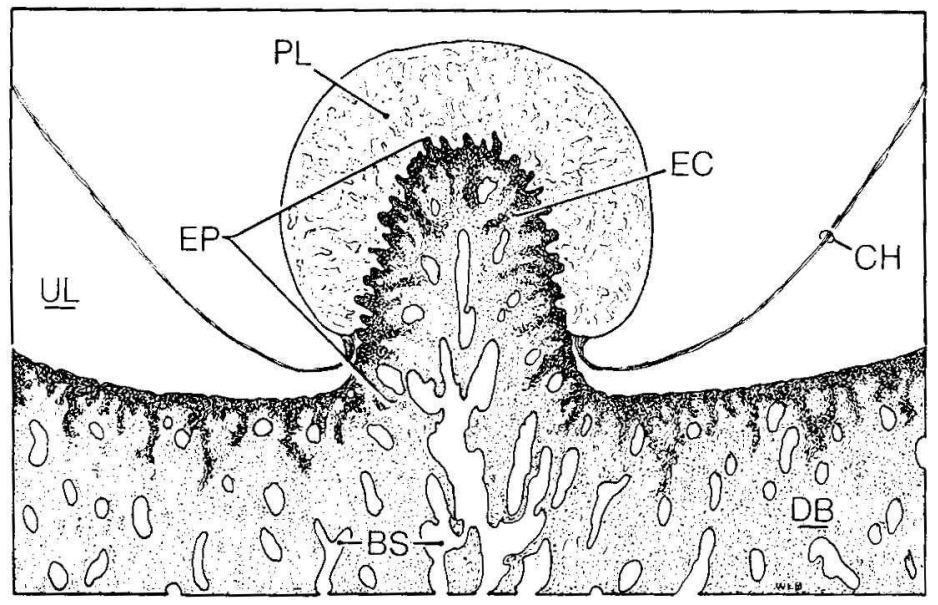

Fig. 3 A diagrammatic sagittal section after contact of the placenta (PL) and endometrial papilla (EP). The chorion ( $\mathrm{CH}$ ) at either pole of the endometrial papilla remains avascular Trophoblastic tongues (light) of the placenta invade the epithelial cords (EC) of the papilla. The blood sinusoids (BS) of the papilla are continuous with veins of the decidual basalis (DB). Uterine lumen, UL. 
rich blood supply associated with the epithelial cords (fig. 3 ). Coincident with the formation of this endometrial papilla, the conceptus expands and the chorion (or perhaps the allanto-chorion, Willey, '14) contacts and surrounds its summit.

\section{Early choriocllantoic placentation}

Two specimens in early limb bud stages were studied. By this time a spheroidal placenta 4 to $5 \mathrm{~mm}$ in diameter has formed around the endometrial papilla (figs. 3, 16). A loose vascular mesenchyme covers the free placental surface and sends penetrating villus cores into the placenta at irregular intervals (fig. 14). These cores branch extensively and intercommunicate to form the basis for a complex lobulate placental architecture. The thick trophoblast which fills the spaces between mesenchymal cores contains tubules which conduct maternal blood (figs. 14, 15).

Maternal blood is carried to trophoblastic arterial channels at the placental surface. It is distributed to the wide trophoblastic tubules and flow centrally toward the endometrial papilla. The trophoblastic tubule at this stage is trilaminar, composed of a cytotrophoblastic layer next to the villus mesenchyme, an apparently syncytial layer, and a cellular layer next to maternal blood (fig. 15).

At the zone of junction with maternal tissue, tongues of proliferating syntrophoblast replace the now degenerative epithelial cords of the endometrial papilla (figs. 16, 17) and erode some of the underlying venous sinusoids. Maternal blood from the trophoblastic tubules drains into them.

\section{Fetal membranes at maturity}

Bilaminar omphalopleure and decidua parietalis. Upon opening the thin antimesometrial uterine wall, a thick dark mass of extravasated blood is encountered. Microscopic examination of the antimesometrial wall fails to show any trace of the uterine epithelium or the bilaminar omphalopleure. The latter is present, however, adhering to the uterine wall of the mesometrial side and ends of the gestation sacs. Here Reichert's membrane and a layer of mononuclear primary giant cells are prominent.
No decidua capsularis ever develops in the beaver, so the zonary decidua parietalis is broad, composed of stroma of the entire antimesometrial and lateral uterine walls. Maternal blood seeps through the denuded decidua parietalis into the yolk sac cavity. Removal of this extravasated blood reveals the dark brown vascular yolk sac (fig. 4).

Vascular splanchnopleure. The yolk sac gradually becomes inverted over the growing fetus until, at midterm, it almost completely encloses the conceptus. At its line of reflection to the bilaminar omphalopleure, it attaches to the avascular chorion and the placental base (figs. 5,6). Only a transitory apposition of chorion and yolk sac as a choriovitelline placenta was observed in an early preplacental stage.

The yolk sac is well supplied with blood via branches of the large vitelline arteries (figs. 4, 18). A large branch of each reaches the edge of the vascular splanchnopleure to form an anastomosing sinus terminalis around its border (fig. 6). This sinus terminalis borders the avascular chorion at each end of the gestation sac and is attached to the sides of the placental base.

The endodermal surface of the yolk sac is raised by many ridges and villi which project into the pool of extravasated maternal erythrocytes in the yolk sac cavity. The yolk sac is given a dark brown color by the intense phagocytic activity of the endodermal cells. Many contain ingested erythrocytes and pigment granules. These granules give a positive ferrocyanide reaction, indicating the presence of iron (fig. 18). A probable function of the vascular splanchnopleure, therefore, would be to provide an entrance for iron into the fetus.

Chorion. The chorion consists of two flask-shaped avascular membranes continuous with either pole of the placental base by a narrow pedicle, but elsewhere surrounded by the sinus terminalis of the vascular yolk sac (fig. 6). The expanded chorionic areas are stretched as drumbeads across the ends of the gestation sac, and separate the uterine lumen from the extraembryonic coelom.

Allantois. The allantois is present to term as a large fluid-filled sac situated atop the placenta (figs. $4,5,8$ ). Its duct is patent at all times. Although the allantoic meso- 


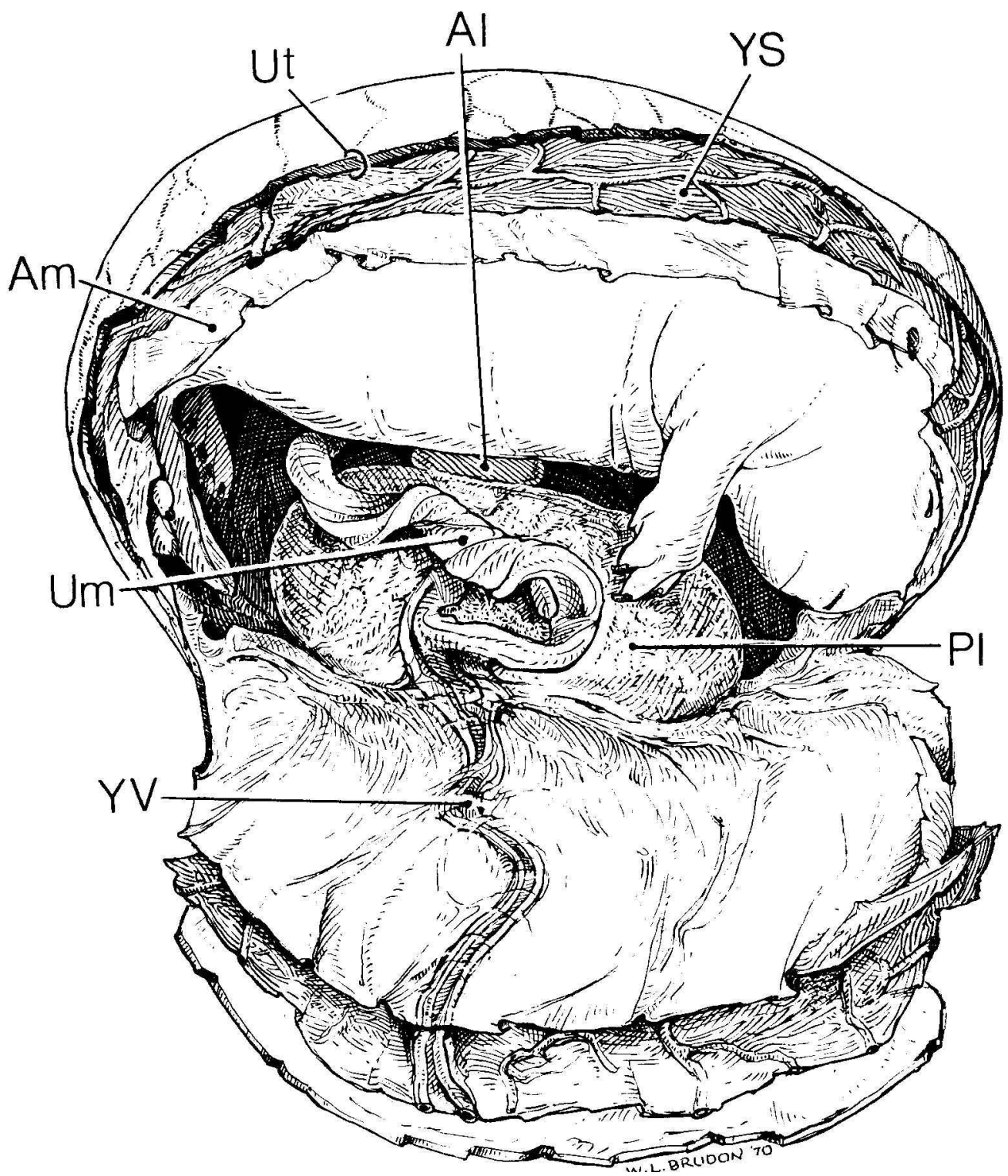

Fig. 4 Gestation sac opened in the last half of pregnancy. The vascular yolk sac (YS) is inverted around the conceptus and contacts the uterine wall (Ut). Yolk sac vessels (YV) leave the umbilical cord (UM) at one side of the placenta (P1) and are closely invested by the amnion (Am). The large allantois ( $\mathrm{Al}$ ) is located atop the placenta.

derm is responsible for the vascularization of the placenta, the allantoic sac itself is rather sparsely vascularized.

Amnion. The amnion is extensive at this stage. It is a free membrane immediately central to the vascular yolk sac, but is firmly attached in a ring around the placental base (fig. 5). It is loosely attached to the placental and allantoic surfaces and closely surrounds the vitelline vessels as they leave the umbilical cord for the yolk sac (figs. 4,23 ). 


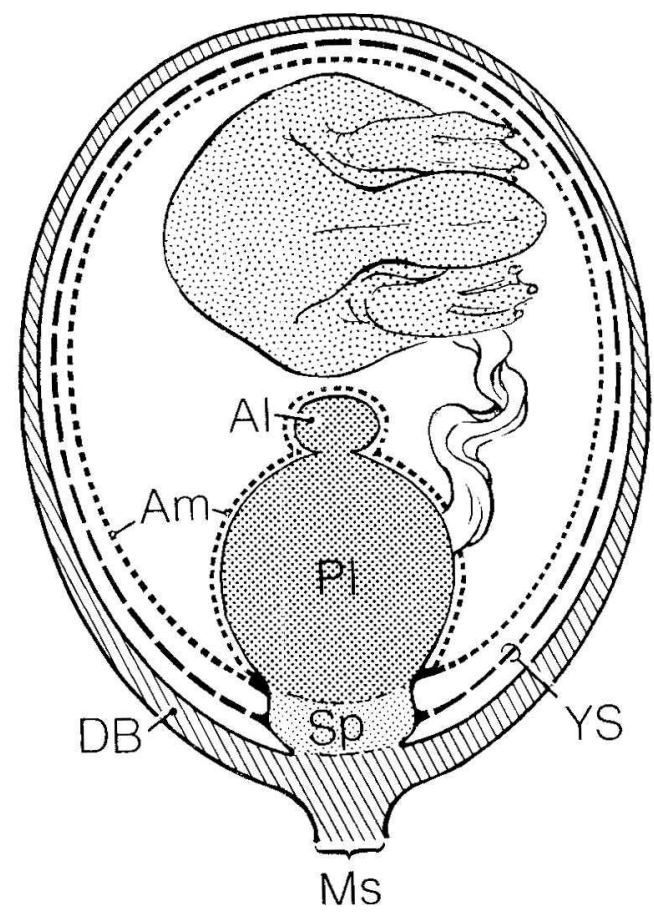

Fig. 5 Diagrammatic cross section of a gestation sac in the second half of pregnancy. The extent and attachment of the yolk sac (YS) to the subplacenta ( $\mathrm{Sp}$ ), and of the ammion (Am) to the placental labyrinth (PI) and allantois (AI) is demonstrated. Mesometrium, MS; decidua basalis, DB.

\section{The mature placenta}

The beaver placenta is a reniform organ which is attached to the basal decidua by a broad pedicle (figs. $4,5,19$ ). Its bulk is made up of a labyrinthine zona intima (area of physiologic interchange) which rests upon a specialized base, or subplacenta. This subplacenta spreads out to form a spongy cushion between labyrinth and basal decidua (fig. 19).

Blood supply. Maternal blood is supplied by one large artery on either side of the placenta (figs. 7,19 ). As it ascends within the basal decidua, the muscular walls of the placental artery are replaced with a thick eosinophilic, PAS positive sheath of necrotic tissue. As the artery approaches the subplacenta, round trophoblastic cells infiltrate the necrotic sheath and come to line the lumen of the vessel (fig. 20). This luminal trophoblastic lining also extends in a retrograde direction for some distance into the artery.

Upon entering the subplacenta, the arterial necrotic sheath becomes considerably thinned and increasing numbers of trophoblastic cells infiltrate it. The arterial channel ascends toward the labyrinth, surrounded by a specialized sheath of subplacental tissue (fig. 21). At the subplacental-labyrinth interface the channel turns laterally to the free surface of the placenta (figs. 7,19 ), and aquires a wall of several layers of trophoblast in place of the necrotic layer and subplacental sheath (fig. 23). It then ramifies in a typical pattern across one side of the placental surface (fig. 7). At no time does either of the two main arterial channels ever traverse the labyrinth itself

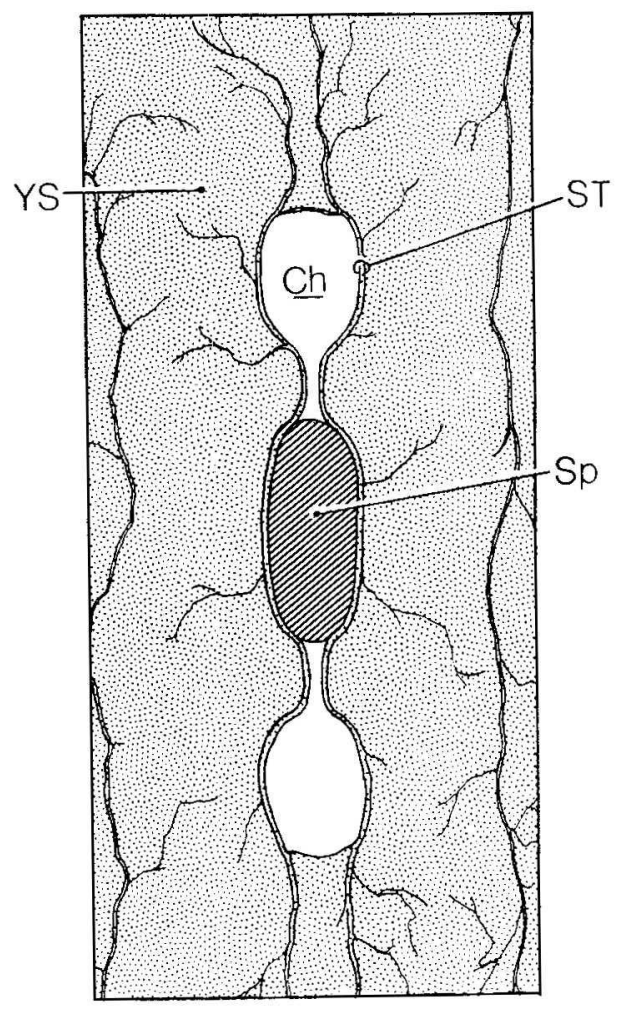

Fig. 6 Diagrammatic view of the central surface of the yolk sac (YS) and chorion (Ch) when the placenta, fetus and other fetal membranes are removed by a section through the subplacenta. The prominent sinus terminalis (ST) of the yolk sac surrounds the flask-shaped chorionic membranes and the cut surface of the subplacenta (Sp). 


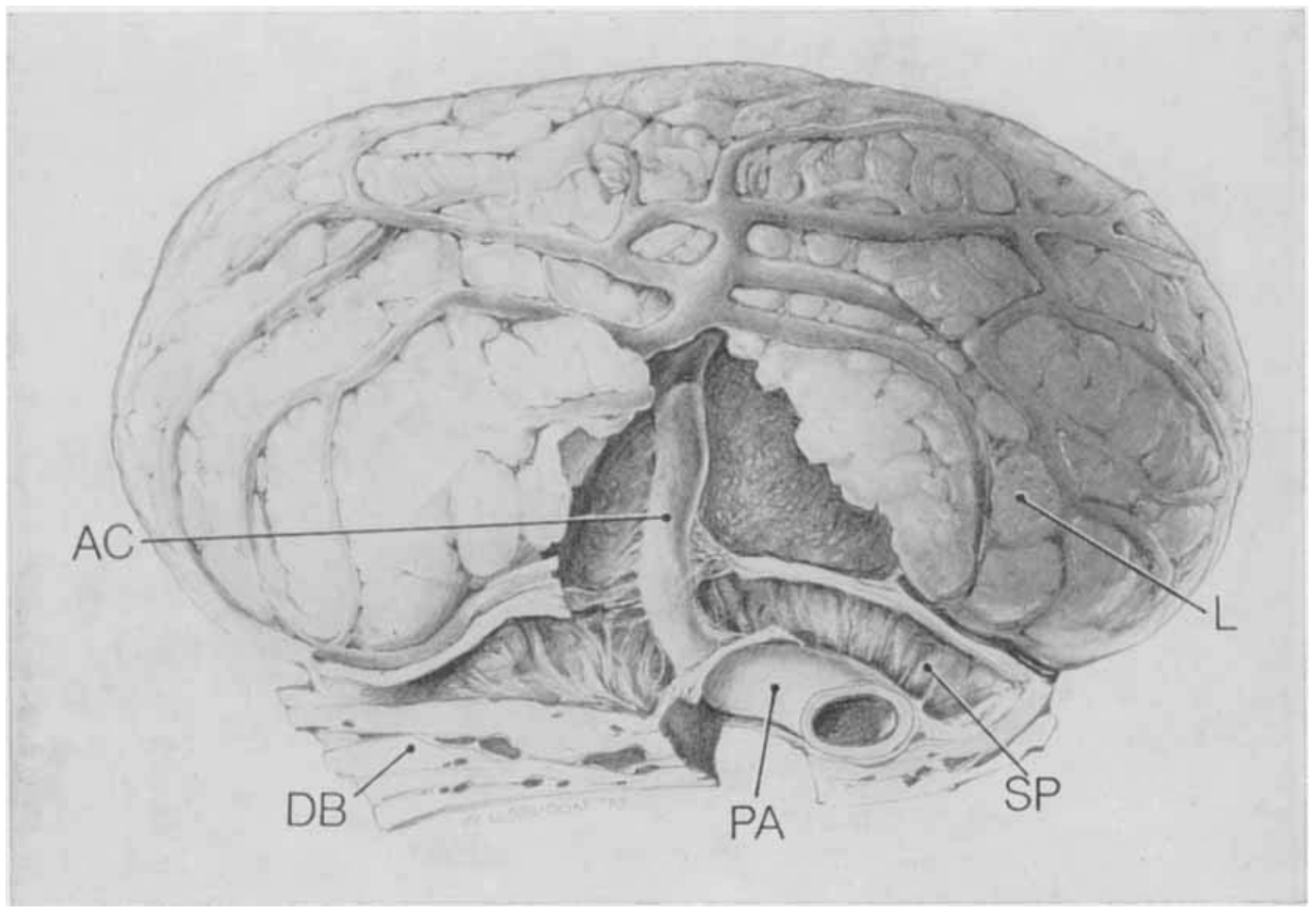

Fig. 7 External view of the placenta demonstrating its maternal blood supply. A sheathed placental artery (PA) courses through the decidua basalis (DB) and the subplacenta (SP), and ascends to the placental labyrinth ( $L$ ) as an arterial channel (AC) surrounded by subplacental tissue (dissected away). It ramifies upon one side of the placental surface in this typical pattern.

on its way to the surface, differing in this manner from other rodents.

Venous drainage. Maternal arterial blood flowing in channels across the placental surface is distributed to numerous trophoblastic tubules which meander toward the center of the placenta. The blood becomes collected into ever larger venous spaces until it finally enters the single maternal venous channel at the subplacental-labyrinth interface (figs. 8, 19, 22). This channel has a short, direct course through the middle of the subplacenta to the veins of the decidua basalis.

The thin walls of the venous channel are composed of a necrotic sheath similar to that of the arterial channels. A layer of trophoblastic cells also lines the luminal surface and extends for a short distance into the decidual veins.

Fetal blood flow. Fetal arteries and veins ramify in a pattern similar to the maternal arterial channels, but superficial to them within the loose mesenchyme of the free surface of the placenta (fig. 23). Their branches descend into the mesenchyme of the villus cores. Arteriolar branches and venous tributaries arise from the parent vessels at frequent intervals in their course through the labyrinth (fig. 23). These arterioles and their capillaries seem to have no constant relationship to the centripetal maternal blood flow. If a counter current blood flow exists in the beaver placenta, its pattern is not obvious in histological sections and must remain an open question.

The labyrinth. The zona intima of the beaver placenta is a labyrinth composed of maternal blood tubules of moderate to large diameter and vascular mesodermal villus cores which project from larger cores of the fetal lobules (fig. 23).

As reported by Mossman ('57) the trophoblastic tubules are distinctly bilaminar at this stage. The outer layer, next to mater- 


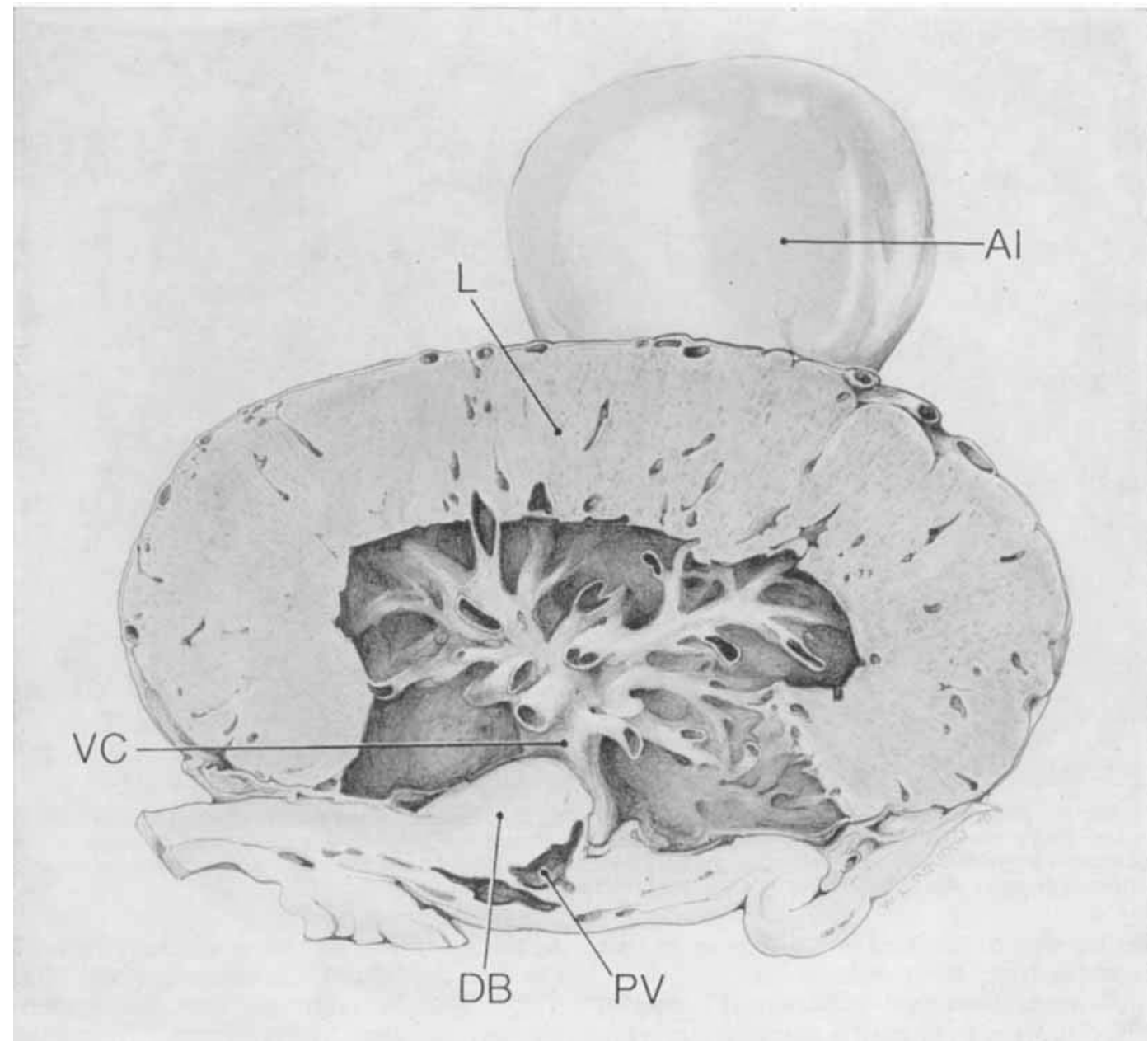

Fig. 8 Sagittal section of the placenta demonstrating the drainage pattern of maternal blood. Trophoblastic tubules in the labyrinth (L) coalesce into short branched channels that join to form a single maternal venous channel (VC) which drains into placental veins (PV) of the decidua basalis (DB). The subplacenta and part of the labyrinth have been dissected away. The voluminous allantoic $\operatorname{sac}(\mathrm{Al})$ is also demonstrated.

nal blood, is cellular and the inner layer appears to be syncytial (fig. 24). A distinct membrane, which stains with Alcian blue and colloidal iron, is present between the two tubule layers (fig. 25). In places, this membrane may also show a weak PAS reaction. No reticular fibers were ever demonstrated here, although the silver deposition method clearly revealed many delicate fibers surrounding fetal capillaries in adjacent mesenchyme (fig. 26).

Electron microscopic examination confirms the outer layer to be cellular and the inner syncytial (fig. 30). Occasional cytotrophoblastic cells occur deep to the inner layer and may be destined to merge with the syntrophoblast. No basal lamina or deposition of any kind appears between inner and outer layers. On the contrary, their plasmalemmas are often in close contact and numerous regions of interlocking microvilli between the two layers occur (fig. 31 ). This is in contrast to endotheliochorial placentae, where a definite basal lamina intervenes between trophoblast and maternal endothelium (King and Tibbits, '69). 
It has been reported that interlocking microvilli of trophoblast and maternal uterine epithelium in the placenta of the mare give a positive colloidal iron reaction, but also that this reaction is common to other microvilli (Wynn, '69). A microvillous reaction such as this may well account for the blue "membrane" which appears after colloidal iron or Alcian blue staining for light microscopy. Thus, unlike the endotheliochorial condition in some heteromyid rodents (King and Tibbits, '69), or that of the vampire bat, where maternal endothelium is transient (Bjorkman and Wimsatt, '68), there is no evidence for maternal endothelium in the beaver labyrinth at any time. The two complete trophoblastic layers compose a hemodichorial placental barrier, according to the nomenclature of Enders ('65).

\section{The subplacenta}

Early stages. One of the most unusual features of beaver placentation is the subplacenta. It has just begun to form in early stages of placentation and is well developed at midterm.

The endometrial papilla, which forms the center of the placental area in early placentation, has a vascular center surrounded by dense connective tissue (fig. 16). At its periphery, enclosed by the thick placental cap, is an area where the cells of the uterine epithelium and epithelial cords coalesce to form a degenerating symplasmic mass (figs. 16, 17).

Numerous syntrophoblastic sprouts, continuous with the inner layer of the labyrinth, penetrate between and into the degenerating cords. The adjacent mesenchyme follows the syntrophoblastic invasion. The cellular (outer) trophoblastic layer of the labyrinth also keeps pace with the syntrophoblast, proliferating and filling the spaces around and between adjacent syntrophoblastic tongues (fig. 17).

Although the stages immediately following are unavailable, it is likely that continued centripetal invasion by trophoblast will replace the maternal tissues, and the veins and sinusoids will become vascular channels surrounded by trophoblast.

This phenomenon is similar to the condition in Sciuridae, where syntrophoblast invades degenerating glands (Mossman and
Weisfeldt, '39). As in the ground squirrel, the maternal epithelium forms a symplasmic mass in advance of the syntrophoblast which replaces it.

Definitive subplacenta. At maturity the subplacenta presents a strange appearance. The endometrial papilla has completely disappeared. Numerous mesenchymal villus cores extend from the labyrinth to the basal decidua (figs. 19, 27, 28). These cores are quite vascular and are surrounded by trophoblast, which electron microscopy reveals to be a single layer of syntrophoblast (fig. 32). A few inner cytotrophoblastic cells are also present.

Between these villi is a mass composed of round vacuolated cells, extravasated blood cells and abundant intra- and extracellular glycogen (figs. 27, 28, 29). Many of the round cells appear disrupted or with pycnotic nuclei, but scattered areas contain apparently healthy cells, many being in mitosis. No connective tissue, capillaries or reticular fibers are present between the villi. Electron micrographs of the intervillous area show that entire cells, erythrocytes, and cell constituents such as glycogen granules, rough endoplasmic reticulum, mitochondria and lipid droplets are mixed together in general disorder (figs. 32, 33).

The intact cells resemble those of the outer layer of the trophoblastic tubules of the labyrinth. Similarities of mitochondria, rough endoplasmic reticulum and glycogen content suggest that they may in fact represent the outer layer cells in the subplacenta. Such cells were certainly present between syntrophoblastic tongues in early subplacental formation. Other evidence indicating a trophoblastic origin is the presence of a necrotic zone separating these cells from unmistakable decidua basalis (fig. 28). Such necrosis is to be expected at maternal-fetal interfaces (Wynn, '69).

\section{DISCUSSION}

\section{Function of the subplacenta}

The function of an organ such as the subplacenta is an enigma. In the guinea pig, the subplacenta seems certain to be a site of placental growth; at maturity it is gone. The guinea pig subplacenta may be important in gonadotropic hormone production (Davies et al., '61). 
In the beaver, the subplacenta is not necessary for growth, for cytotrophoblast internal to the labyrinth syncytium evidently gives rise to new syntrophoblast interstitially, much as in man. Basal accretion would not be an important method of placental growth.

The possibility remains that the round trophoblastic cells of the subplacenta may secrete gonadotropic hormones. The cells contain abundant rough endoplasmic reticulum and glycogen, appearing capable of protein secretion. The disruption of many of the cells would argue against their physiologic activity, but this may well be artifactual, since the organelles are quite well preserved even when extruded.

There is no true preplacenta or trophospongium in the beaver. The subplacenta may, however, represent the beginning of a trend toward it. The round cells are continuous with outer layer of cells in the labyrinth in the same manner as the trophospongial cells of other rodents (e.g., Pedetes, Fischer and Mossman, '69) are continuous with the corresponding labyrinthal layer. Although there is no directed blood flow through the subplacenta as there is through trophospongium, a slow extravasion of maternal blood from the labyrinth into the subplacenta does occur. These two bits of evidence may indicate a homology of subplacenta and trophospongium.

\section{The phylogenetic status of the Castoroidea}

Most of the features of placentation in Castor would point to a primitive phylogenetic position (table 1). Primitive features possessed in common with the suborder Scriuomorpha include: (1) superficial implantation, (2) a large preplacental blastocyst, (3) late inversion of the germ layers, (4) a permanent chorion, (5) amniogenesis by folding, (6) no ectoplacental cone, preplacenta or trophospongium, (7) coarse trophoblastic blood tubules, and (8) a permanent allantoic vesicle. A characteristic typical of somewhat more specialized rodents is the late disappearance of the bilaminar omphalopleure.

The unique characteristics of beaver placentation are the formation of a spheroidal placenta around a central endometrial papilla, and the replacement of this maternal papilla by a highly specialized subpla-
TABLE 1

Synopsis of basic data on the fetal membranes of Castor

Implantation

Orientation of disc: mesometrial.

Orientation of first attachment: antimesometrial.

Depth: superficial; multiple attachment cones.

Decidua: no capsularis; broad, zonory parietalis; late formation of basal decidua cells.

Amniogenesis: folding.

Chorion: flask-shaped at either end of placental base; persisting to term.

Yolk sac

Bilaminar omphalopleure: lost near midterm, except near its junction with the vascular yolk sac where it persists to term.

Chorio-vitelline placenta: very early and temporary.

Vascular splanchnopleure: complete inversion at midterm; villous overall, but more pronounced on mesometrial hemisphere; extensively phagocytoses maternal erythrocytes.

Chorio-allantoic placenta

Shape: reniform.

Internal structure: labyxinthine; lobulate.

Finer morphology: hemodichorial.

Location: mesometrial.

Accessory placentae: subplacenta of fetal villi and round trophoblast cells; function unknown.

Allantoic vesicle: moderately large; persists to term.

centa of fetal origin. Both the histological structure and the mode of formation of this subplacenta are unlike that of the caviomorph rodents (Davies et al., '61). Rather, the degeneration of the maternal epithelial cords and their subsequent invasion and replacement by trophoblast is reminiscent of placental formation in the Sciuridae (Mossman and Weisfeldt, '39).

Because of their many primitive features and the resemblance of their specializations to other processes known in Sciuromorpha, the fetal membrane characters of Castor indicate a close relationship to this suborder. Indeed, little evidence from fetal membranes would link the Castoroidea to any other group.

\section{ACKNOWLEDGMENTS}

The early stages of beaver placental tissues were provided by The Hubrecht Laboratory, Utrecht, Holland. Mr. Kenneth 
Jones, Manistique, Michigan, collected tissues from midterm specimens. Dr. H. W. Mossman, University of Wisconsin, Madison, Wisconsin, generously supplied fresh material from near-term animals for light and electron microscopy. I am indebted to Mr. William Brudon, Department of Anatomy, The University of Michigan, for the art work of the text-figures, and to $\mathrm{Mr}$. Grayson Scott, Department of Anatomy, The Universiy of Wisconsin, for technical preparation and photography of the electron microscopic figures.

\section{LITERATURE CITED}

Bjorlkman, N. H., and W. A. Wimsatt 1968 The allantoic placenta of the vampire bat (Desmodus rotundus murinus). A reinterpretation of its structure based on electron microscopic observations. Anat. Rec., 162: 83-98.

Davies, J., E. Dempsey and E. Amoroso 1961 The subplacenta of the guinea pig: development, histology and histochemistry. J. Anat., 95: $457-473$.

Enders, A. C. 1965 A comparative study of the fine structure of the trophoblast in several hemochorial placentas. Am. J. Anat., 116: 29-68.

Fischer, T. V., and H. W. Mossman 1969 The fetal membranes of Pedetes capensis, and their taxonomic significance. Am. J. Anat, 124: 87116.
King, B. F., and F. D. Tibbits 1969 The ultrastructure of the placental labyrinth in the kangaroo rat, Dipodomys. Anat. Rec., 163: 543-554.

Mossman, H. W. 1937 Comparative morphogenesis of the fetal membranes and accessory uterine structures, Contr. Embry, Carnegie Inst., Wash., 26: 126-246.

1953 The genital system and the fetal membranes as criteria for mammalian phylo. geny and taxonomy. J. Mammal., 34: 289-298. 1957 Endotheliochorial placentation in the rodents, Castor and Pedetes. Proc. Zool. Soc., Calcutta, Mookerjee Mem. Vol.: 183-189.

Mossman, H. W., and L. S. Weisfeldt 1939 The fetal membranes of a primitive rodent, the thirteen-striped ground squirrel. Am. J. Anat., 64: 59-109.

Movat, H. Z. 1955 Demonstration of all connective tissue elements in a single section. A. M. A. Arch. Path., 60: 289-295.

Orsini, M. W. 1954 The trophoblastic giant cells and endovascular cells associated with pregnancy in the hamster, Cricetus auratus. Am. J. Anat., 95: 273-331.

Romer, A. S. 1966 Vertebrate Paleontology. Third edition. University of Chicago Press, Chicago.

Willey, A. 1912 Foetal membranes of the American beaver (Castor canadensis). Zool. Jahrb., Suppl. 15 (vol. 2): 191-218.

1914 The blastocyst and placenta of the beaver. Quart. J. Micr. Sci., 60: 175-259.

Wynn, R. M. 1969 Non-cellular components of the placenta. Am. J. Obst. Gyn., 103: 723-739. 
Abbreviations

AC, maternal arterial channel

Cap, capillary

Cyt, cytotrophoblast

$\mathrm{DB}$, decidua basalis

DP, decidua parietalis

Ec, ectoderm

En, endoderm

FV, fetal blood vessel

$\mathrm{L}$, Jabyrinth

Mes, mesenchyme

OC, outer cellular trophoblast

$\mathrm{RTr}$, round subplacental

trophoblast cell

Sp, subplacenta

Syn, syntrophoblast

Tr, trophoblast

TT, trophoblastic tubule

Ue, uterine epithelium

$\mathrm{UL}$, uterine lumen

$\mathrm{V}$, fetal villus

$\mathrm{VC}$, maternal venous channel

All figures are oriented with the mesometrial side down.

PLATE 1

EXPLANATION OF FIGURES

9 Pre placental blastocyst. Note the superficial antimesometrial attachment and the precocious development of a trilaminar embryonic disc on. the right side of the "keel" on the mesometrial hemisphere (arrow). $\times 40$

10 Detail of embryonic disc from figure 9. The superficial ectoderm is continuous with trophoblast and is separated from the endoderm by extensions of mesoderm (Me) from the primitive streak area. $\times 150$.

11 Detail of attachment area from figure 9 , showing three attachment cones (arrows) penetrating the uterine epithelium. $\times 150$.

12 Antimesometrial trophoblast of a preplacental blastocyst older than that in figure 9. Some attachment cones have disappeared and a layer of primary trophoblast giant cells (GC) are forming within the unattached blastocyst surface. $\times 30$.

13 Detail of blastocyst surface from figure 12. Leucocytes (arrows) may be seen in the decidua parietalis, the uterine lumen, and within the row of seven giant cells. $\times 150$. 

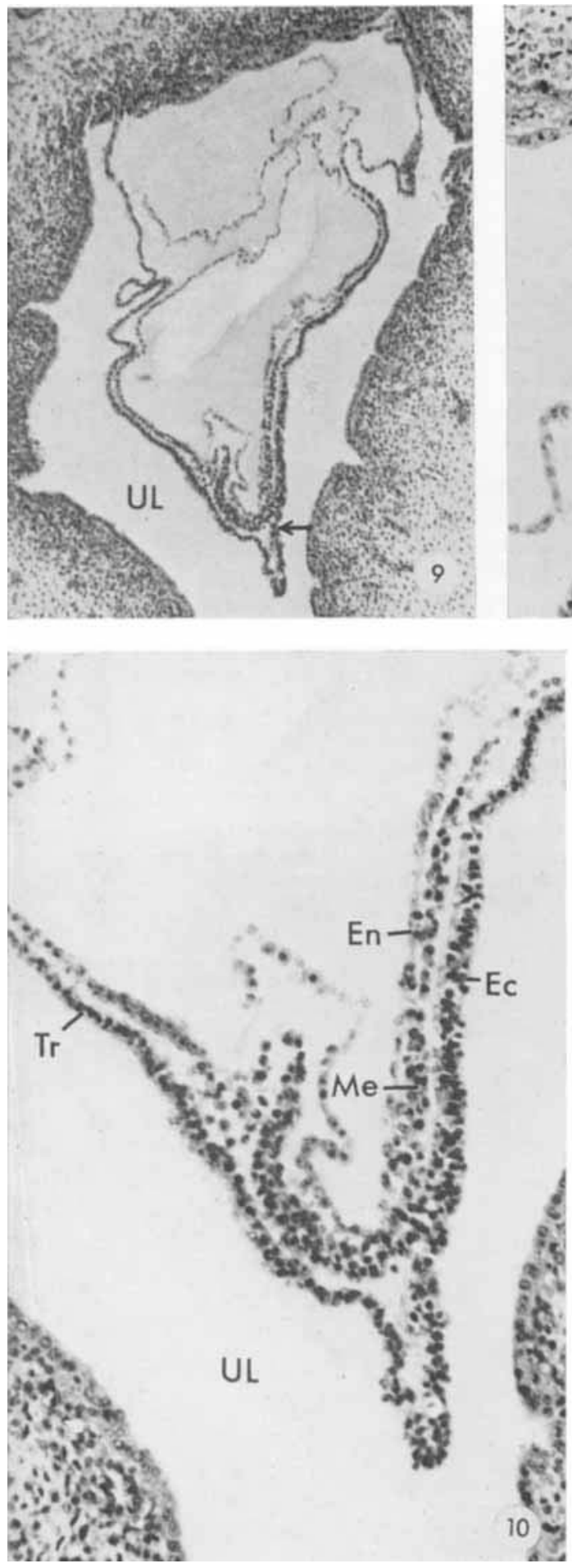
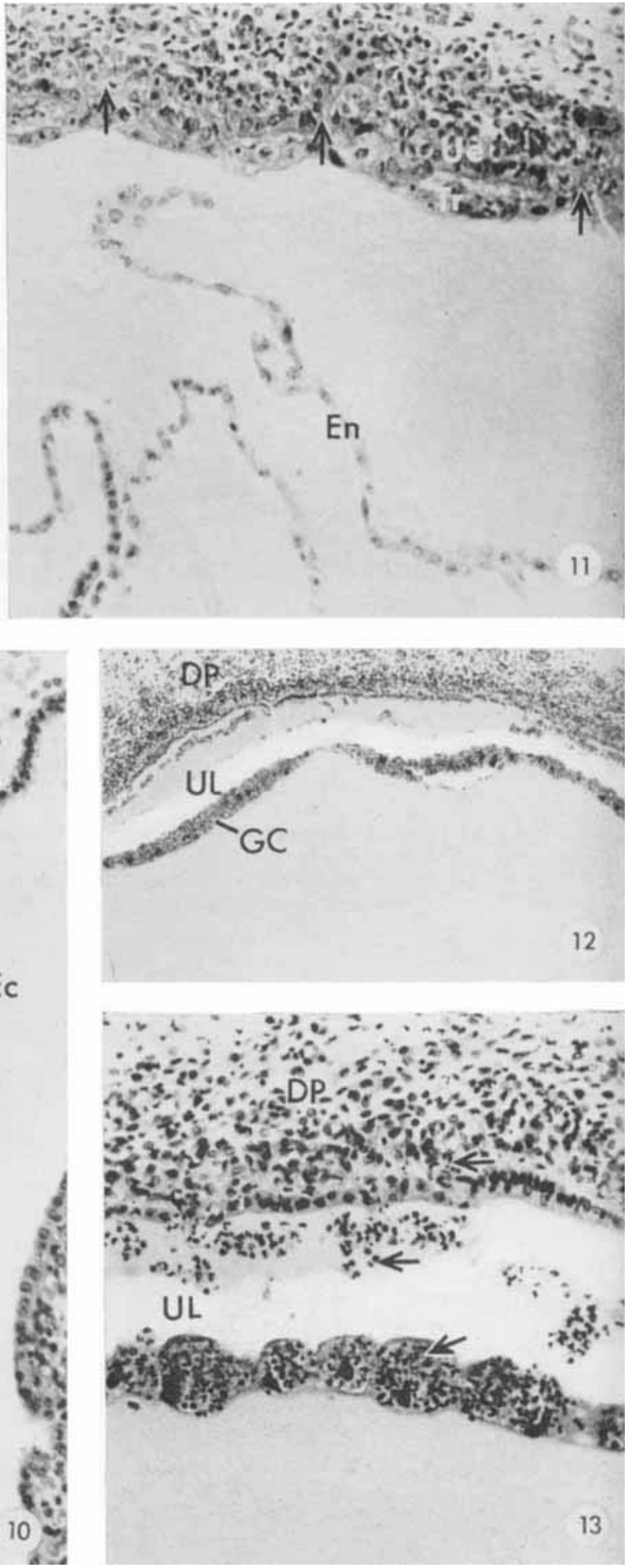
PLATE 2

EXPLANATION OF FIGURES

14 Labyrinth of early placenta. Vascular villous cores separate thick trophoblastic cords and laminae. $\times 40$.

15 Trophoblastic tubule carrying maternal blood. A fetal vessel runs in the adjacent mesenchyme. The three layers of tronhoblast: inner cytotrophoblast, middle syntrophoblast, and outer cellular layer are all distinct. A mitotic figure occurs in the cellular layer (arrow) $\times 2015$.

16 Junction of endometrial papilla (EP) and early placenta. Degenerating epithelial cords border the vascular papilla center (arrows). Syntrophoblast from the surrounding placenta is beginning to invade these cords (arrowheads), $\times 40$.

17 Detail of trophoblast - epithelial junction from figure 16. The epithelial cords (EC) have degenerated to symplasmic masses which are being replaced by fast-growing syntrophoblast. Cytotrophoblast (arrows) proliferates between tongues of syntrophoblast. $\times 150$. 

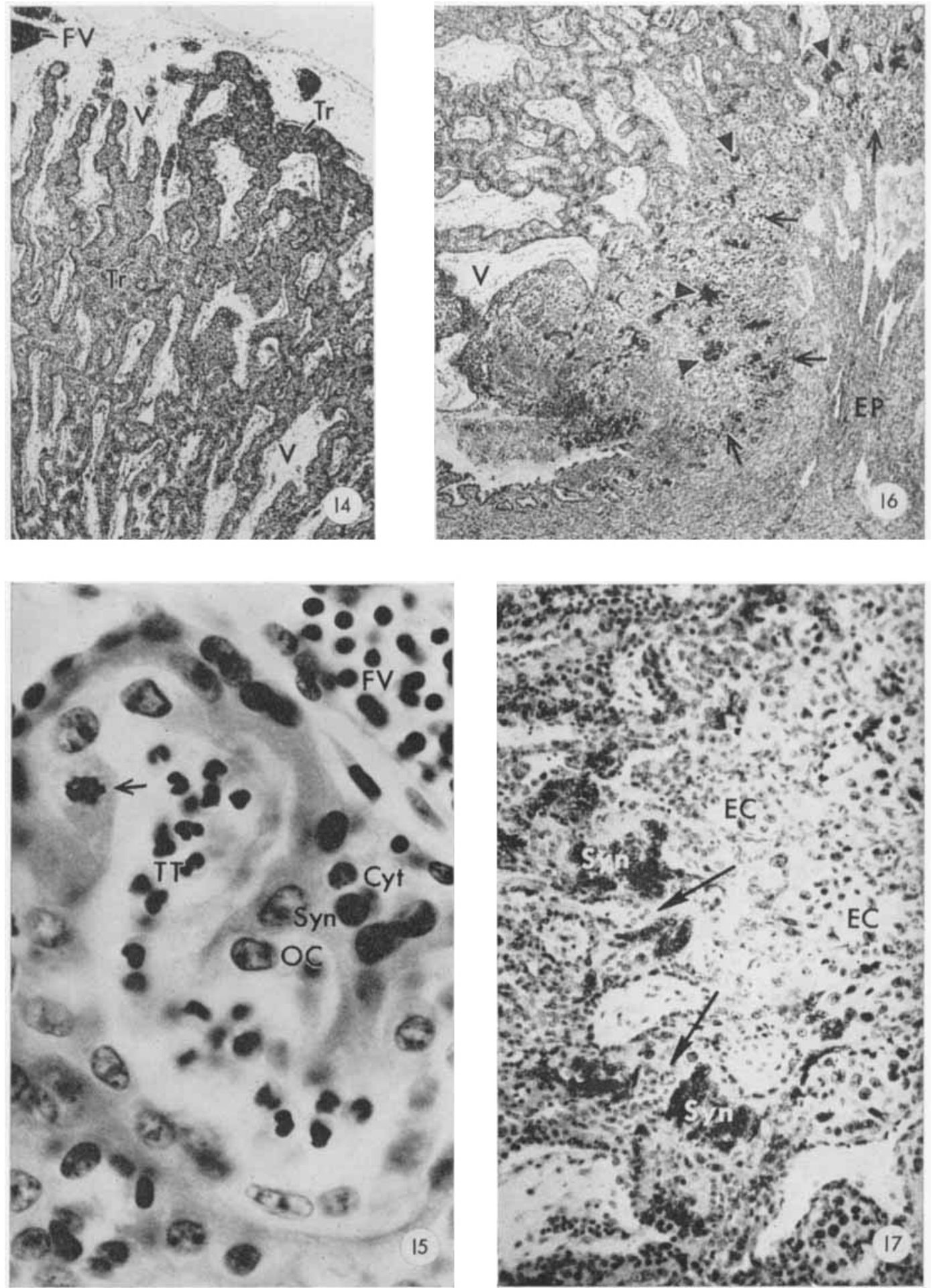
18 Vascular yolk sac. The ferrocyanide reaction demonstrates abundant iron in the endodermal cells. Yolk sac villi and blood vessels are prominent. $\times 150$.

19 Cross section of a mature placenta. The labyririth is penetrated by mesenchymal villus cores, and is situated above the subplacenta. The spongy subplacenta is separated by a narrow necrotic zone (arrow) from the decidua basilis. Two lateral maternal arterial channels and a central maternal venous channel penetrate the subplacenta. $\times 3.5$.

20 Arterial channel within the decidua basalis. The normal wall is replaced with a necrotic sheath (Sh) and is infiltrated and lined by trophoblast cells. $\times 935$.

21 Arterial channel approaching the labyrinth. The trophoblastic lining and necrotic sheath are reduced, but a thick subplacental sheath surrounds the channel. $\times 40$. 
Theodore V. Fischer

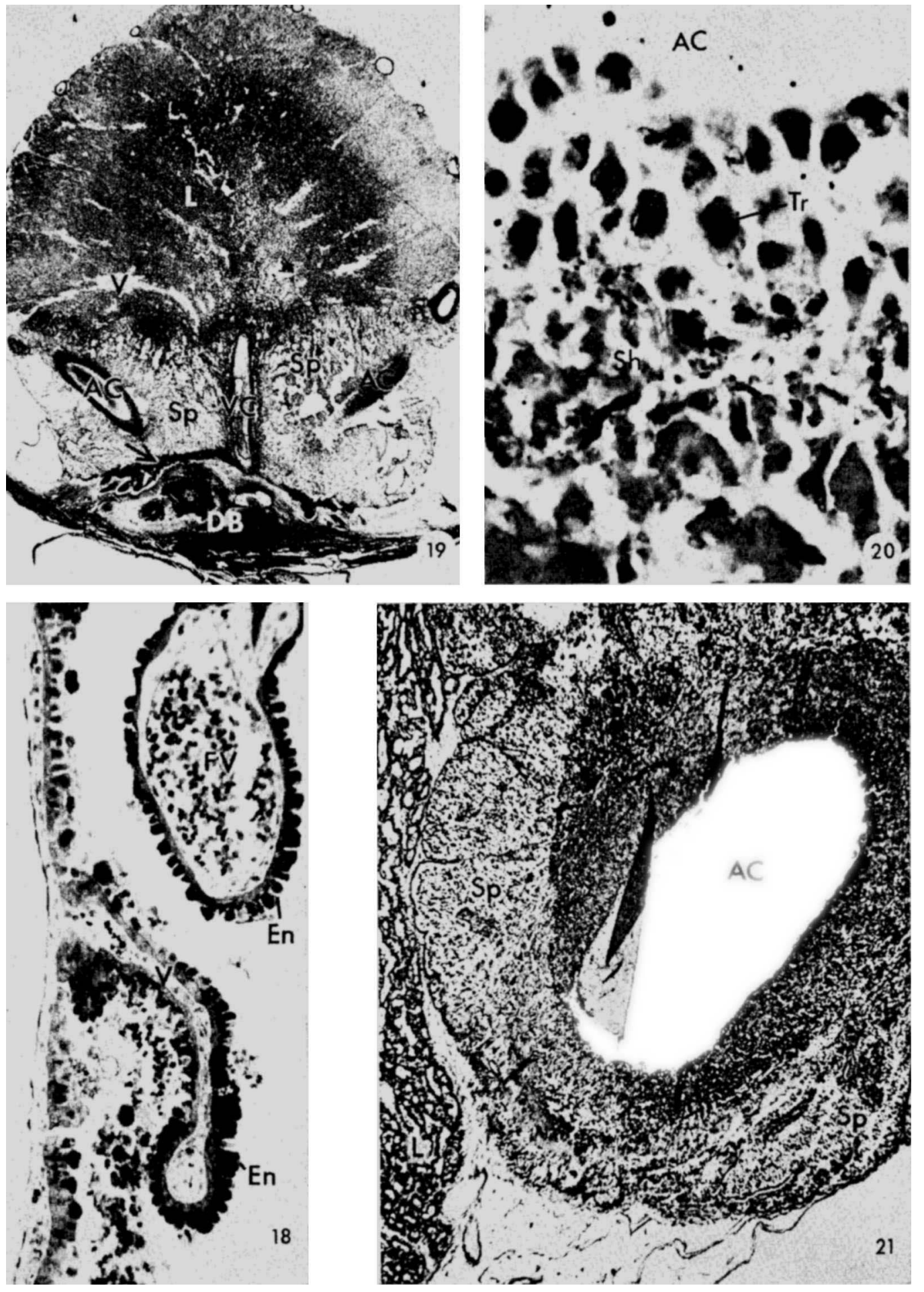


PLATE 4

EXPLANATION OF FIGURES

22. Coalescence of trophoblastic tubules near center of labyrinth. $\times 40$.

23 Labyrinth near free surface of placenta. The amnion (Am) is loosely attached to the placental surface. Fetal vessels cross the placenta superficial to the maternal channels and distribute to the branching villous cores. Coarse trophoblastic tubules are evident (arrows) $\times 40$.

24. Trophoblastic tubules surrounding vascular mesenchyme. The cellular outer layer is distinct from the inner syntrophoblast (arrow). $\times 935$.

25 Several trophoblastic tubules stained with Alcian blue. A dark stain. ing membrane (arrows) is often present between cellular and syntrophoblast layers. $\times 1000$.

26 Trophoblastic tubule and adjacent mesenchyme demonstrated by silver deposition. Reticular fibers (arrows) are present in the mesenchyme but not between trophoblastic layers. $\times 935$. 

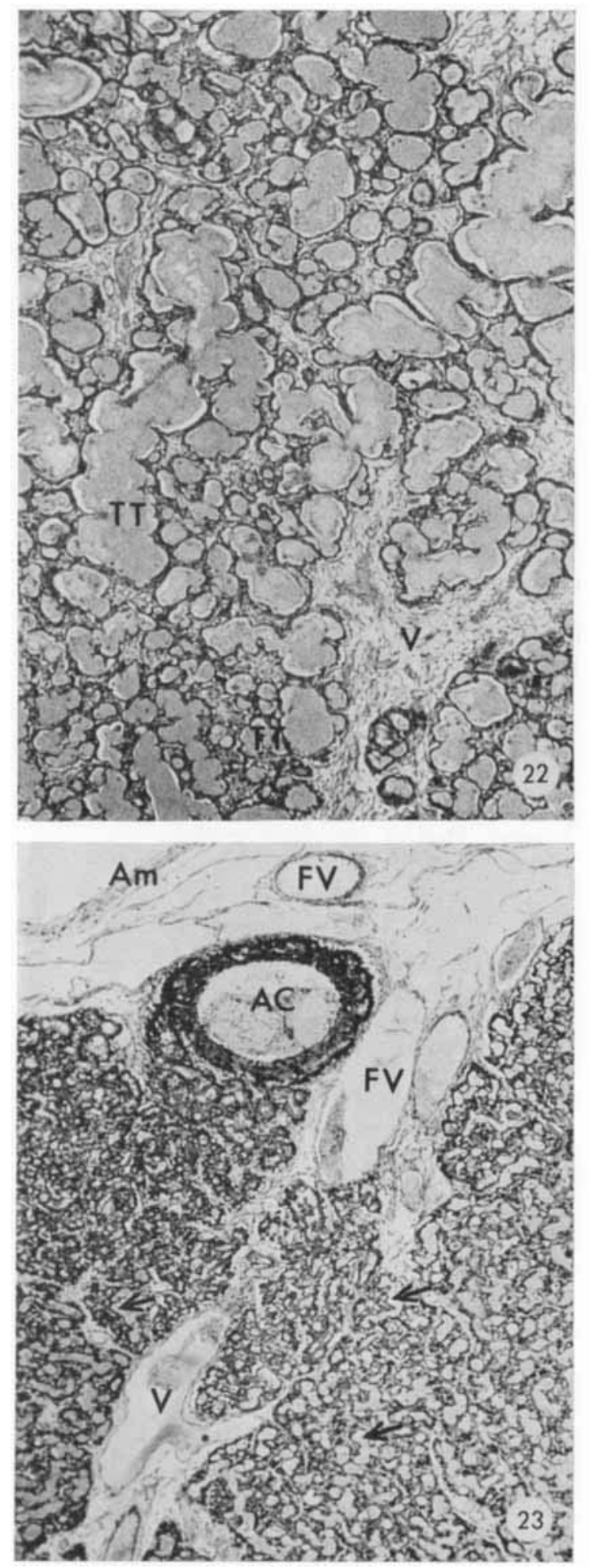
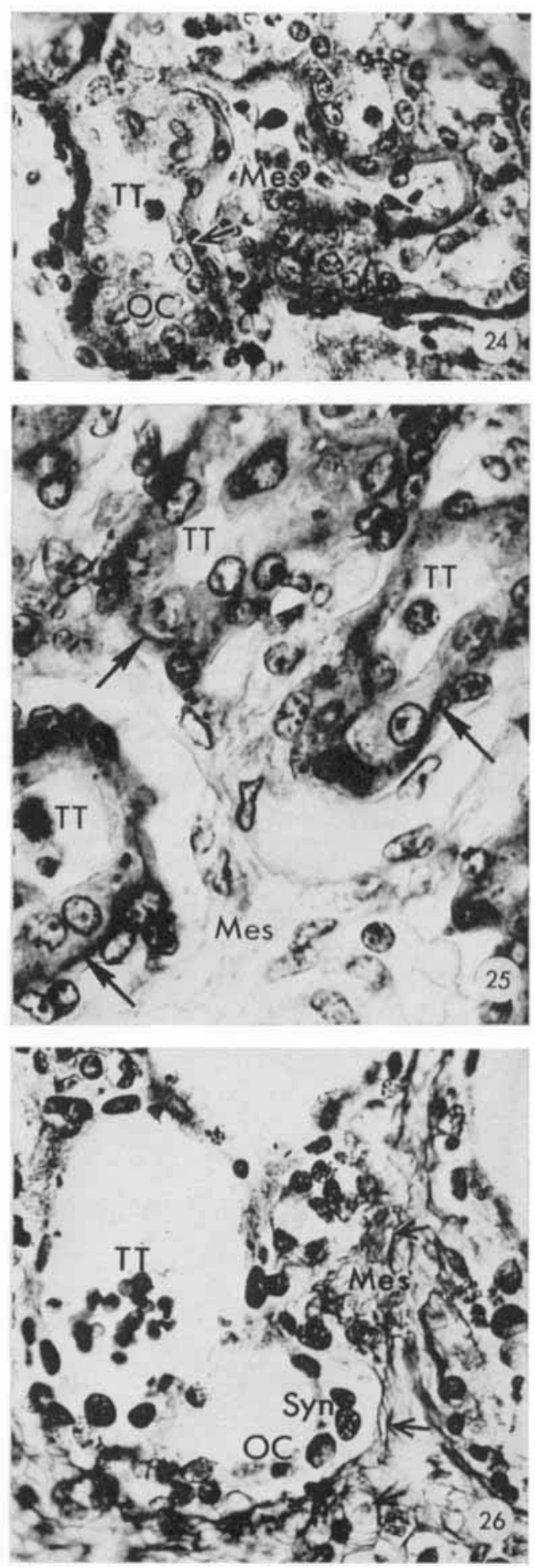


\section{PLATE 5}

EXPLANATION OF FIGURES

27 Subplacental - labyrinth interface. Villus cores from the labyrinth penetrate the subplacenta. Subplacental spaces between villi are loosely filled with round trophoblastic cells and extravasated maternal erythrocytes. $\times 40$.

28 Zone of junction between subplacenta and decidua basalis. Subplacental villi and round trophoblast cells abut on a dark band of necrotic decidua separating them from viable maternal tissue. $\times 40$.

29 Detail of subplacenta. Villi are quite vascular, and are covered by a single layer of syntrophoblast (arrows). Most of the round trophoblastic cells between villi appear vacuolated or disrupted. $\times 150$. 

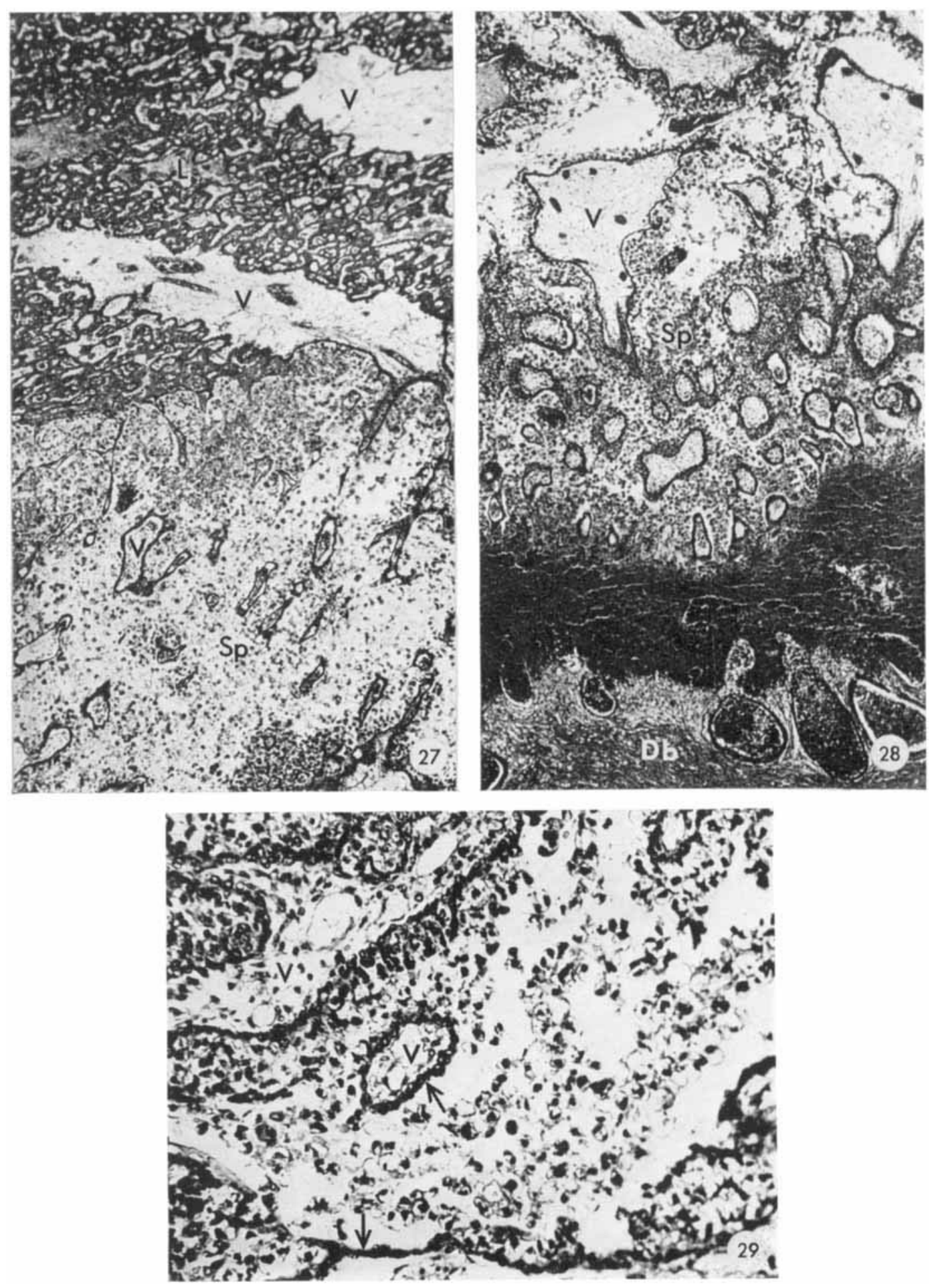
PLATE 6

EXPLANATION OF FIGURES

30 Trophoblast of the labyrinth. A uniform inner syntrophoblastic layer partially surrounds a fetal capillary. Several large outer layer cells, lining the maternal blood space (MB), have numerous microvilli (MV) which interdigitate with those of the synthrophoblast. $\times 1540$.

31 Labyrinth trophoblast. Several outer layer cells overlap, but only the one in contact with syntrophoblast possesses microvilli (MV). $\times 11,400$. 

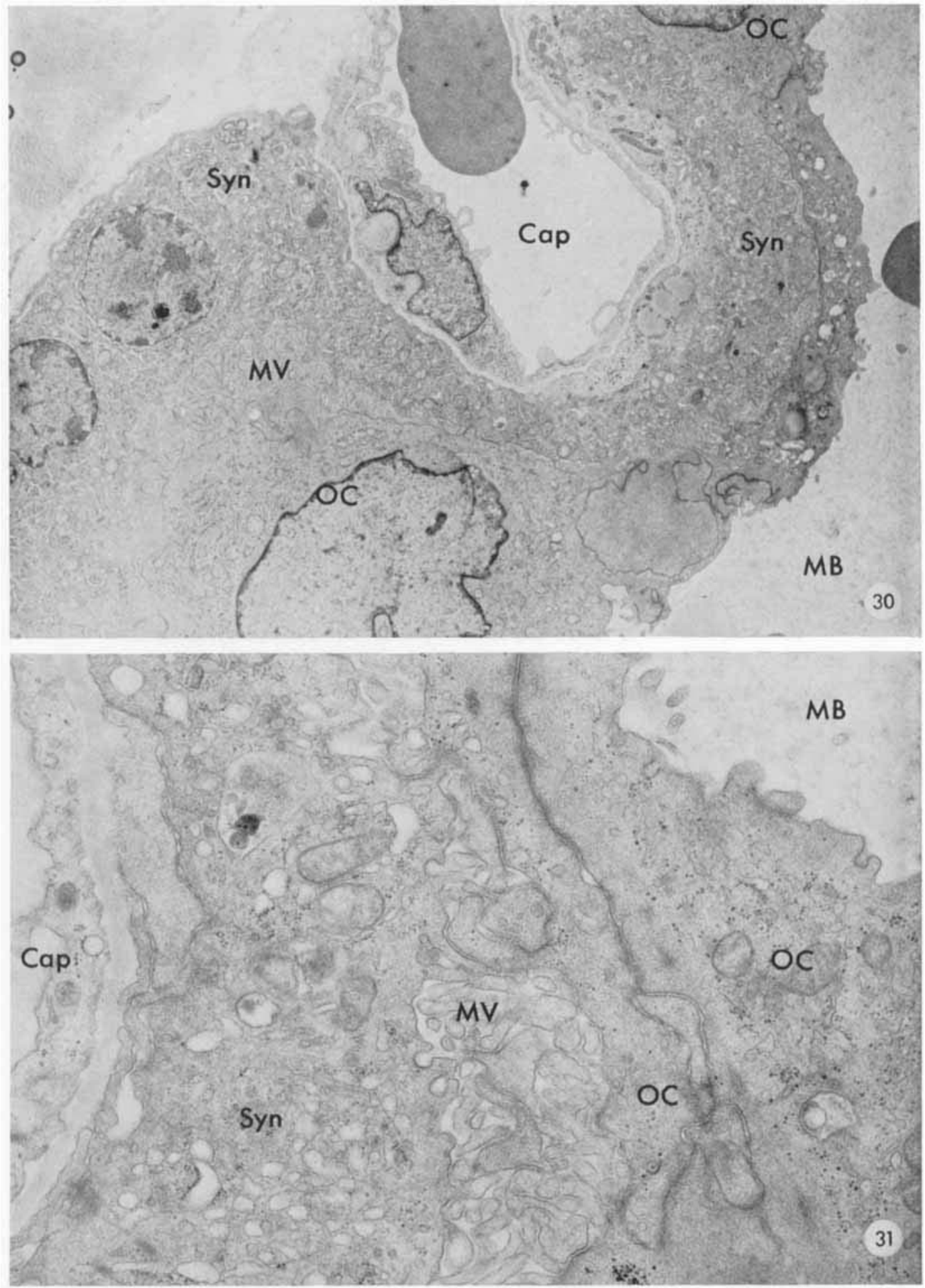
PLATE 7

EXPLANATION OF FIGURES

32 Subplacenta. The fetal villus is covered by a single layer of syntrophoblast and scattered inner cytotrophoblast cells. It contains loose vascular mesenchyme. The intervillous space is filled with round trophoblast cells and disrupted cells and their organelles. $\times 1540$.

33 Subplacenta. A round trophoblast cell in the intervillous space is ruptured at one point (arrow) and is seen disgorging its contents. An extravasated maternal erythrocyte (RC) is also present in this space. $\times 2400$. 
Theodore V. Fischer
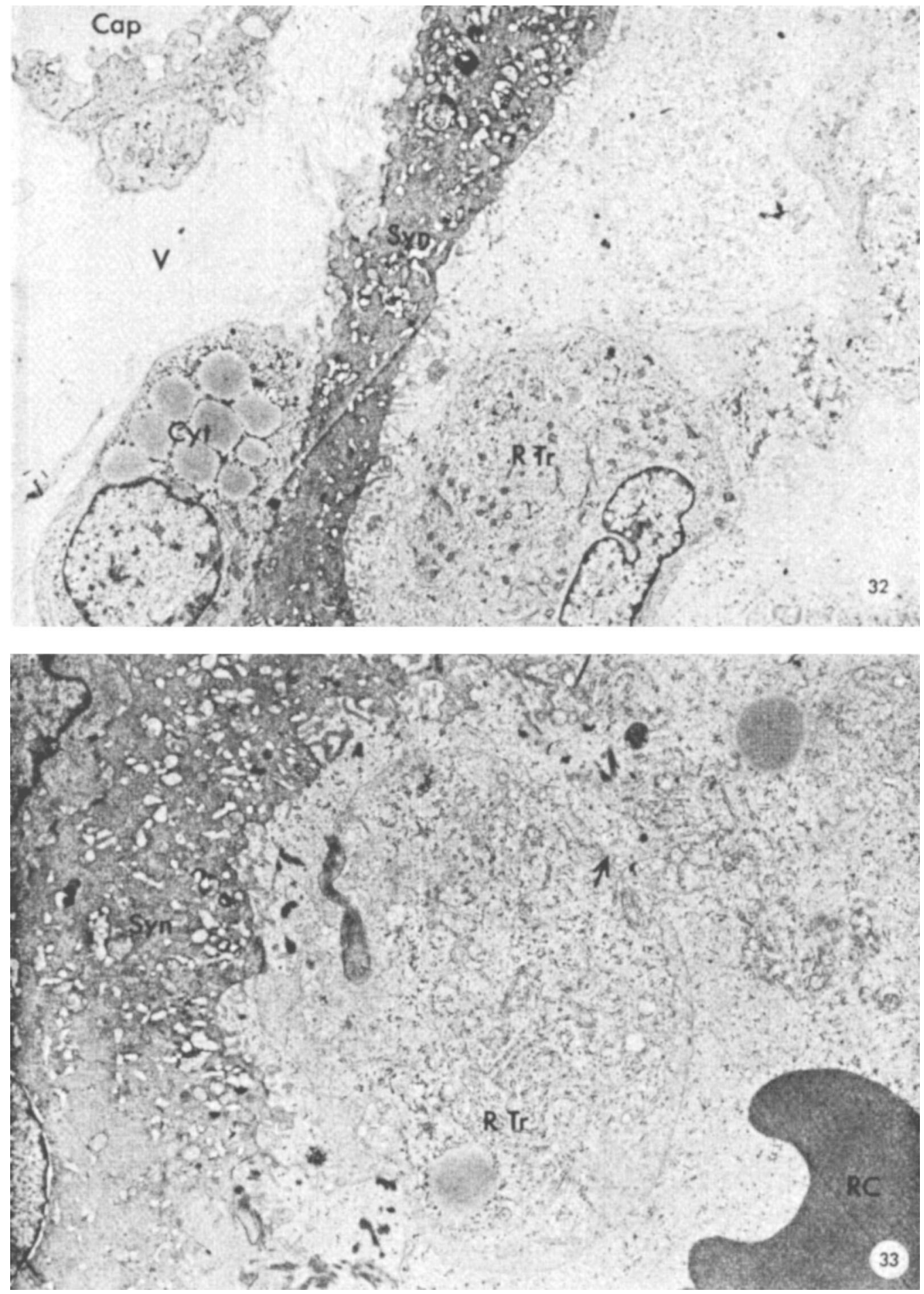